\title{
gem-Selective Cross-Dimerization and Trimerization of Alkynes with Silylacetylenes Promoted by a Rhodium-Pyridine-N-Heterocyclic Carbene Catalyst
}

\author{
Ramón Azpíroz, ${ }^{[\mathrm{a}]}$ Laura Rubio-Pérez, ${ }^{[\mathrm{a}]}$ Ricardo Castarlenas, ${ }^{\text {[a],[b] }}$ Jesús J. Pérez- \\ Torrente, ${ }^{[\mathrm{a}]}$ and Luis A. Oro*[a],[c]
}

Dedication ((optional))

gem-Selective cross-dimerization and trimerization of silylacetylenes with alkynes via $\mathrm{C}-\mathrm{H}$ activation using a rhodium(I)-pyridine- $\mathrm{N}$ heterocyclic carbene catalyst have been developed. This protocol is applicable to variety of aliphatic or aromatic terminal alkynes, internal alkynes and gem-1,3-disubsituted enynes to afford the corresponding enynes and dienynes with high regio- and stereoselectivities and good isolated yields (up to $91 \%$ ).

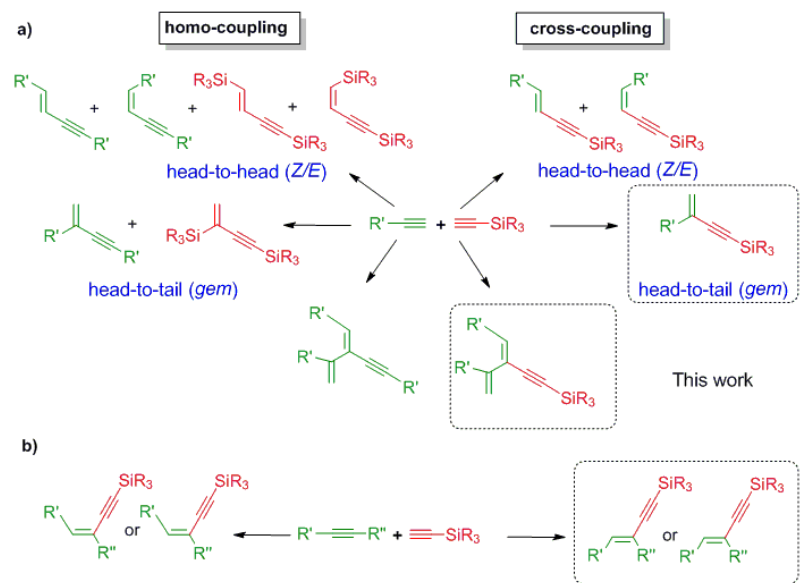

Scheme 1. Possible products from cross-coupling of silylacetylene derivatives with alkynes: a) terminal, b) internal. Compounds prepared in this work in dashed lines.

Our research group has been developing new efficient and selective catalytic systems for $\mathrm{C}-\mathrm{C}$ and $\mathrm{C}$-heteroatom coupling

[a] Dipl.-Chem. Ramón Azpíroz Dr. Laura Rubio-Pérez, Dr. R. Castarlenas, Prof. J. J. Pérez-Torrente and Prof. L. A. Oro Departamento de Química Inorgánica-ISQCH

Universidad de Zaragoza - CSIC

Facultad de Ciencias, C/Pedro Cerbuna 12, 50009, Zaragoza-

Spain.

E-mail: rcastar@unizar.es, oro@unizar.es

[b] Dr. R. Castarlenas

$A R A I D$ Foundation researcher.

[c] Prof. L. A. Oro

Center of Research Excellence in Refining \& Petrochemicals King Fahd University of Petroleum \& Minerals, Dhahran, 31261, Saudi Arabia. 
reactions based on rhodium-N-heterocyclic carbene (NHC) metal complexes. ${ }^{[13]}$ Particularly, dinuclear compounds of type $\left[\mathrm{Rh}(\mu-\mathrm{Cl})(\mathrm{NHC})\left(\eta^{2} \text {-olefin }\right)\right]_{2}$, (1) have been revealed as valuable starting materials for the preparation of mononuclear complexes of type $\mathrm{RhCl}(\mathrm{NHC})\left(\eta^{2}\right.$-olefin)(L) (2), by simple bridge-cleavage with a nuchleophilic ligand..$^{[13 d-h]}$ These derivatives exhibited excellent performance in catalytic alkyne hydrothiolation, ${ }^{[13 d, h]}$ and in the preparation of $4 \mathrm{H}$-quinolizines via $\mathrm{C}-\mathrm{H}$ activation. ${ }^{[13 \mathrm{e}]}$ Indeed, it has also been found that complex $\operatorname{RhCl}(\operatorname{IPr})\left(\eta^{2}\right.$ coe)(py) (2a) [IPr = 1,3-bis-(2,6-diisopropylphenyl)imidazol-2carbene, coe $=$ cyclooctene, py $=$ pyridine $]$ promotes the selective homo-dimerization of alkynes to head-to-tail enynes, in which the chemo- and regioselectivity is controlled by the addition of pyridine. ${ }^{[13 f]}$ Now, we report an efficient chemo-, regio-, and stereoselective Markonikov-type cross-dimerization and trimerization involving trimethylsilylacetylene and aliphatic and aromatic terminal alkynes, internal alkynes and gem-1,3disubstituted enynes.

\section{Results and Discussion}

Cross-dimerization of trimethylsilylacetylene with terminal alkynes. The catalytic system $2 \mathbf{a}+10$ equiv of pyridine ${ }^{[14]}$ was tested for the cross-dimerization of trimethylsilylacetylene (3a) with phenylacetylene (4a) (Table 1 , Scheme 2). At $40{ }^{\circ} \mathrm{C}$, the reaction is fully selective to head-to-tail $(\mathrm{gem})$ dimerization products being prevalent the phenylacetylene homodimerization enyne $7 a$ (entry 1). However, we observed that selectivity changes dramatically with the temperature. At $60^{\circ} \mathrm{C}$, a $37 \%$ of cross- phenylacetyle-trimethylsilylacetylene dimerization product $5 \mathbf{a}$ and $50 \%$ of phenylacetylene homodimerization derivative 7 a was obtained (entry 2). Interestingly at $80{ }^{\circ} \mathrm{C}$, the cross-coupled compound $\mathbf{5 a}$ was the major product $(81 \%)$ with a $5 \%$ of homo-dimerization product 7 a (entry 3$)$. In both cases, the formation of the trimer $8 \mathbf{a}(\sim 14 \%)$, resulting from the coupling of two molecules of phenylacetylene with trimethylsilylacetylene, was also observed as a by-product. The observed temperature effect over the selectivity is probably due to a modification of the overall kinetic parameters, indicating that at high temperature the $\mathrm{C}-\mathrm{H}$ activation plays a preeminent role, thereby favouring cross dimerization. Moreover, an excess amount of pyridine accelerates the crossdimerization to form $\mathbf{5 a}$ with good chemo- and regioselectivity. Noteworthy, when dinuclear complexes $\mathbf{1}$, lacking of a pyridine ligand, were used as catalysts, no dimerization products were formed, but the presence of cyclotrimers was observed instead, as described in our previous work. ${ }^{[13 f]}$

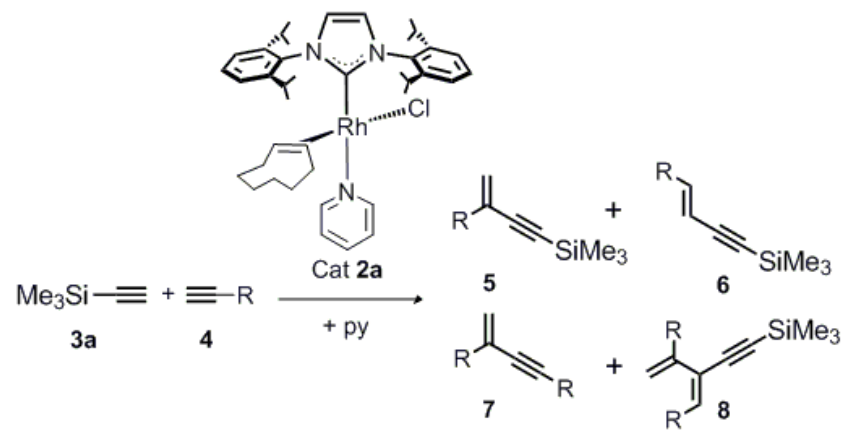

Scheme 2. Catalytic transformation of alkynes with $\mathbf{2 a}+10$ equiv py.

\begin{tabular}{|c|c|c|c|c|c|c|c|}
\hline Entry 1 & $t(h)$ & $\mathrm{T}\left({ }^{\circ} \mathrm{C}\right)$ & Conv \% & $5 a$ & $6 a$ & $7 a$ & $8 a$ \\
\hline 1 & 3 & 40 & 65 & 18 & -- & 82 & -- \\
\hline 2 & 3 & 60 & 99 & 37 & -- & 50 & 13 \\
\hline 3 & 2 & 80 & 99 & 81 & -- & 5 & 14 \\
\hline
\end{tabular}

[a] Reaction conditions: $0.5 \mathrm{~mL}$ of $\mathrm{C}_{6} \mathrm{D}_{6}, 0.2 \mathrm{mmol}$ of $3 \mathrm{a}, 0.2 \mathrm{mmol}$ of $4 \mathrm{a}, 0.01$ of catalysts $2 \mathrm{a}+0.1 \mathrm{mmol}$ of pyridine.

The unequivocal characterization of the head-to-tail crossdimerization product $\mathbf{5 a}$, was achieved by comparison with the reported ${ }^{1} \mathrm{H}$ and ${ }^{13} \mathrm{C}\left\{{ }^{1} \mathrm{H}\right\}$ NMR data ${ }^{[15]}$ and the heteronuclear correlation ${ }^{1} \mathrm{H}^{13} \mathrm{C}$ HMBC experiment. The more significant part of the 2D-NMR spectrum is shown in Figure 1. The terminal olefinic protons ( $\delta 5.80$ and $5.77 \mathrm{ppm}$ ) display correlation peak with one $\mathrm{C}_{\mathrm{sp}}$ carbon atom $(\delta 104.8 \mathrm{ppm})$, whereas, more significantly, the other alkynyl carbon atom ( $\delta 95.9 \mathrm{ppm})$ interacts with the protons of the trimethylsilyl group ( $\delta 0.31 \mathrm{ppm})$ and not with the aromatic protons, discarding the phenyl-alkynyl connectivity. Indeed, correlation between the gem-protons and the ipso-phenyl quaternary carbon ( $\delta 137.3 \mathrm{ppm}$ ) was also observed (See Supporting Information).

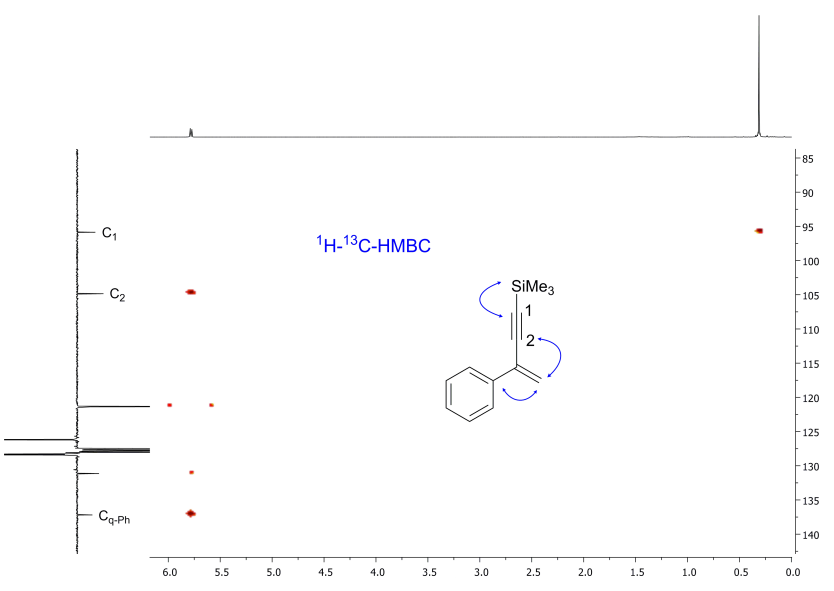

Figure 1. ${ }^{1} \mathrm{H}-{ }^{13} \mathrm{C} \mathrm{HMBC}$ spectrum of compound $\mathbf{5 a}$ in $\mathrm{C}_{6} \mathrm{D}_{6}$.

Then, we have studied the scope of the cross-dimerization reaction between terminal alkynes and trimethylsilylacetylene (Table 2). In general, full alkyne conversion was attained in 1-4 hours to give the corresponding gem-1,3-disubstituted enynes (5) which were isolated in good yields (up to $80 \%$ ). Cross $E$ enynes (6), homo-dimerization derivatives (7), and gemdienyne trimers (8) were also formed in variable amounts. As general trend, aromatic alkynes react faster than aliphatic alkynes (entries 1-4 vs 6-12). Phenylacetylene was almost completely consumed after 2 hours to afford gem-5a with $81 \%$ selectivity (entry 1). Substituted phenylacetylenes bearing an electron-donating group such as -OMe, either at the para or meta position, or tert-butyl, display good regioselectivities and yields (entries 2-4). However, para $\mathrm{CF}_{3}$-substituted substrate $4 \mathrm{e}$ gave exclusively the homo-dimerization product $7 \mathbf{e}$. In the case of aliphatic alkynes, head-to-tail products were obtained as the major product $(>75 \%)$. In contrast with aromatic alkynes, E- 
enynes (6) were also formed in some cases $(<15 \%)$. Thereby, 1-benzylacetylene was transformed in 2 hours leading to $82 \%$ gem-5f (entry 6). 1-hexyne reacted in 3 hours to give $75 \% \mathrm{gem}$ $\mathbf{5 g}$ and $12 \%$ of $E-6 \mathbf{g}$ as main products (entry 7 ). Terminal alkynes bearing $-\mathrm{NMe}_{2}$ and -OMe groups were also crossdimerized with $\mathbf{3 a}$ to form $\mathbf{5 h}$ and $\mathbf{5 i}$ with good yields and regioselectivities (entries 8 and 9 ). The reaction worked equally well with functionalized enynes as 2-methyl-1-buten-3-yne and 1-cyclohexenylacetylene to give gem-dienynes $5 \mathbf{j}$ and $5 \mathbf{k}$, respectively, in good yields and high regioselectivities (entries 10 and 11). Interestingly, 1,7-octadiyne reacted with two equivalents of $\mathbf{3 a}$ to afford the gem-bis-enyne $\mathbf{5 l}$ in good yield, as a result of a double cross-dimerization process (entry 12 and Scheme 3).

\begin{tabular}{|c|c|c|c|c|c|c|c|c|c|}
\hline Entry & Alkyne & & $\mathrm{t}(\mathrm{h})$ & Conv \% & 5 & 6 & 7 & 8 & Yield $\%^{[b]}$ \\
\hline 1 & $\Delta\rangle \equiv$ & $4 a$ & 2 & 99 & 81 & -- & 5 & 14 & $71(5 a)$ \\
\hline 2 & $\equiv$ & $4 b$ & 1 & 99 & 91 & -- & 4 & 5 & $83(\mathbf{5 b})$ \\
\hline 3 & & $4 c$ & 2 & 99 & 85 & -- & -- & 15 & $78(5 c)$ \\
\hline 4 & $\equiv$ & $4 d$ & 2 & 99 & 86 & -- & 10 & 4 & $76(\mathbf{5 d})$ \\
\hline 5 & $\equiv$ & $4 e$ & 1 & 92 & -- & -- & $98^{[c]}$ & -- & $0(\mathbf{5 e})$ \\
\hline 6 & & $4 f$ & 2 & 99 & 82 & -- & 3 & 15 & $70(\mathbf{5 f})$ \\
\hline 7 & 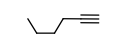 & $4 g$ & 3 & 99 & 75 & 12 & 8 & 5 & $68(5 \mathbf{g})$ \\
\hline 8 & & $4 h$ & 4 & 90 & 81 & 11 & 6 & 2 & $74(5 h)$ \\
\hline 9 & $\mathrm{MeO}=$ & $4 i$ & 4 & 95 & 80 & 12 & -- & 8 & $70(\mathbf{5 i})$ \\
\hline 10 & & $4 j$ & 5 & 98 & 83 & -- & 4 & 13 & $71(\mathbf{5 j})$ \\
\hline 11 & $\Delta=$ & $4 k$ & 3 & 99 & 78 & -- & 22 & -- & $60(\mathbf{5 k})$ \\
\hline 12 & $\equiv$ & $4 !$ & 4 & 99 & 86 & 14 & -- & -- & $80(5 \mathbf{I})$ \\
\hline
\end{tabular}

[a] Reaction conditions: $0.5 \mathrm{~mL}$ of $\mathrm{C}_{6} \mathrm{D}_{6}, 0.2 \mathrm{mmol}$ of $3 \mathrm{a}, 0.2 \mathrm{mmol}$ of $4,0.01$ mol of catalyst $2 \mathbf{a}+0.1 \mathrm{mmol}$ of pyridine at $80^{\circ} \mathrm{C}$. [b] Isolated yield of $\mathbf{5}$. [c] $2 \%$ of $E$-homo-dimer was also observed.

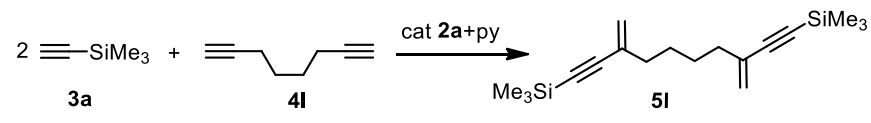

Scheme 3. Double cross-dimerization between 2 equiv of trimethylsilylacetylene and 1 equiv of 1,7 dioctyne.

Cross-trimerization of terminal alkynes with trimethylsilylacetylene. As can be seen in Table 2, aromatic and aliphatic trimers $\mathbf{8}$ were also formed as secondary products in some cases. Most probably these derivatives result from the homocoupling reaction of the corresponding terminal alkyne and a subsequent cross-trimerization with trimethylsilylacetylene. Thus, this process could be a straightforward way to construct $\pi$-conjugated systems. In order to promote the formation of $(E)$-(2-alkynyl)-(1,3-disubstituted)1,3-butadiene derivatives, 8 , as major product, we decided to perform the reaction in two steps. First, the homo-dimerization reaction of the corresponding terminal alkyne was carried out under reaction conditions of our previous reported work using 5 $\mathrm{mol} \%$ of catalyst $2 \mathrm{a}$ and 10 equiv of pyridine at $40{ }^{\circ} \mathrm{C}$ in $\mathrm{C}_{6} \mathrm{D}_{6} \cdot{ }^{[13]]}$ In the second step, trimethylsilylacetylene was added and the crude mixture heated at $80^{\circ} \mathrm{C}$ for $12 \mathrm{~h}$ to form gem-1,3dienynes with high regioselectivity and good isolated yields (Scheme 4). The structure of the dienynes was confirmed by ${ }^{1} \mathrm{H}-{ }^{13} \mathrm{C}$ HMBC and ${ }^{1} \mathrm{H}-{ }^{1} \mathrm{H}$ NOE NMR experiments (See Supporting Information). Reactions of aromatic-substituted gem-1,3-enynes 7 gave good yields of the expected gemdienyne products, eg. $\mathbf{8 a}$ and $\mathbf{8 b}$. Unfortunately, compound $\mathbf{8 e}$ could not be obtained due to the decomposition of dienyne 7e, bearing a para- $\mathrm{C}_{6} \mathrm{H}_{4}-\mathrm{CF}_{3}$ substituent, under reaction conditions. Aliphatic-substituted gem-1,3-enyne arising from benzylacetylene gave $\mathbf{8 f}$ which was isolated in $71 \%$ yield. Heteroatom-substituted and olefin functionalized alkynes also undergoes coupling reaction toward the head-to-tail trimers $\mathbf{8 i}$ and $\mathbf{8 j}$, respectively.

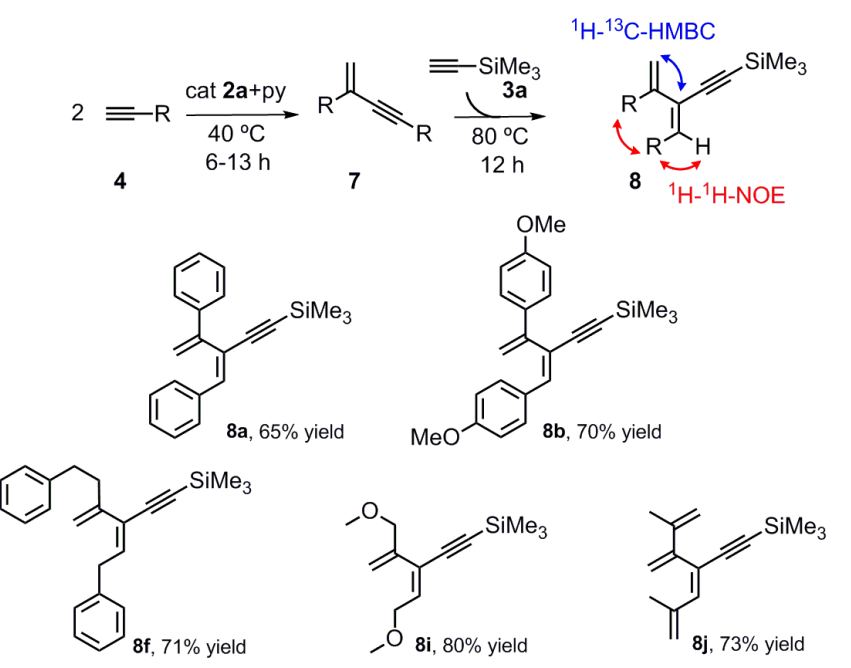

Scheme 4. Rhodium-catalyzed cross-trimerization of terminal alkynes with trimethylsilylacetylene via formation of 1,3-gem enynes.

Cross-dimerization of trialkylsilylacetylenes with internal alkynes. The efficiency of catalyst $\mathbf{2 a}$ was demonstrated for cross-dimerization of internal alkynes (9) with trimethylsilylacetylene (3a) and triisopropylsilylacetylene (3b) (Scheme 5, Table 3). Both silylacetylenes reacted with 3hexyne (9a) and diphenylacetylene (9b) to give preferentially the syn-addition E-enynes 10, which were isolated with moderate to high yields. Formation of thermodinamically more stable Z-enynes $\mathbf{1 1}$ resulted from isomerization of $\mathbf{1 0}$, as observed in prolonged reaction times. Alkyne 3a was slightly more reactive and selective than $3 \mathbf{b}$ (entries $1-2$ vs $4-5$ ). Unsymmetrical internal alkyne such as 1-phenyl-1-propyne (9c) reacted with $\mathbf{3} \mathbf{a}$ to lead preferentially $E$-1-trimethylsilyl-3phenylpent-3-en-1-yne with high yield (entry 3 ). In contrast, with 3b afforded a mixture of E-regioisomers in 40/60 (3-phenyl/4phenyl) ratio (entry 6). 


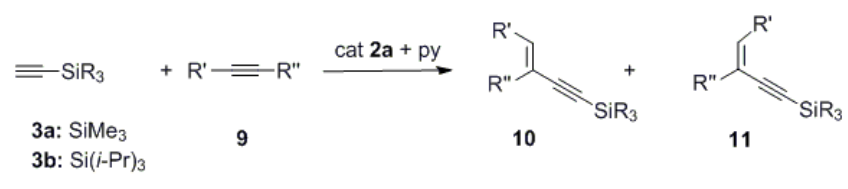

Scheme 5. Cross-dimerization of trialkylsilylacetylenes and internal alkynes.

\begin{tabular}{|c|c|c|c|c|c|c|c|}
\hline Entry & Alkyne & & 3 & $t(h)$ & Conv $\%$ & 10/11 & Yield $^{[b]} \%$ \\
\hline 1 & & $9 a$ & $3 a$ & 12 & 71 & $90 / 10$ & $64(10 a)$ \\
\hline 2 & $\langle\Delta=\langle\Delta\rangle$ & $9 b$ & $3 a$ & 1 & 99 & 100/-- & 91 (10b) \\
\hline 3 & & $9 c$ & $3 a$ & 3 & 92 & $(100 /--)^{[c]} /--$ & $83(10 c)$ \\
\hline 4 & & $9 a$ & $3 b$ & 32 & 93 & $80 / 20$ & $76(\mathbf{1 0 d})$ \\
\hline 5 & $\langle\Delta=\langle\Delta$ & $9 b$ & $3 b$ & 24 & 92 & $82 / 18$ & $75(\mathbf{1 0 e})$ \\
\hline 6 & $y=$ & $9 c$ & $3 b$ & 44 & 90 & $(40 / 60)^{[d]} /--$ & $81(\mathbf{1 0 f})^{[d]}$ \\
\hline
\end{tabular}

[a] Reaction conditions: $0.5 \mathrm{~mL}$ of $\mathrm{C}_{6} \mathrm{D}_{6}, 0.2 \mathrm{mmol}$ of $\mathbf{3 a}$ or $\mathbf{3 b}, 0.2 \mathrm{mmol}$ of 9 $0.01 \mathrm{mmol}$ of catalysts $2 \mathrm{a}+0.1 \mathrm{mmol}$ of pyridine at $80^{\circ} \mathrm{C}$ [b] Isolated yield. [c] $(E)$-1-trimethylsilyl-3-phenylpent-3-en-1-yne derivative as the mayor regioisomer. [d] Isolated as a mixture of regioisomers.

Mechanism of Cross-Dimerization and -Trimerization of Terminal Alkynes. A plausible mechanism for head-to-tail cross-dimerization (a) and head-to-tail cross-trimerization (b) is shown in Scheme 6. This reaction probably proceeds by a similar mechanism to that proposed for the Rh-catalyzed dimerization of terminal alkynes. ${ }^{[13 f]}$ The first step involves the substitution of the cyclooctene ligand by the alkyne and subsequent oxidative addition generates $\mathrm{Rh}^{\mathrm{III}}$-alkynyl-hydride intermediates. Then, alkyne or gem-1,3-enyne insertion can proceed by two pathways: carbometalation via 1,2 insertion (Path I) or hydrometalation via 2,1 insertion (Path II). Finally, reductive elimination affords the corresponding enynes or dienynes and the coordination of a second alkyne or gem-1,3enynes into the metal regenerates the $\mathrm{Rh}^{\prime}$ active species. The selectivity outcome seems to be governed by two key facts. i) $\mathrm{C}-\mathrm{H}$ activation of trimethylsilylacetylene in the first step should be favoured versus that of aromatic or aliphatic alkynes due to its higher acidity, ${ }^{[11]}$ and ii) the bulkier trimethylsilyl group hampers the insertion step for this substrate, thus, aliphatic and aromatic alkynes react faster. The acidity increase of the alkyne by incorporation of a $-\mathrm{CF}_{3}$ group in 1-ethynyl-4(trifluoromethyl)benzene (4e) could explain the observed preferential homo-dimerization of this alkyne. Finally, it is worth mentioning the beneficial effect of using an excess of pyridine which should play a crucial role in the catalytic cycle for stabilization of rhodium-alkynyl-hydride intermediates. ${ }^{[13]]}$
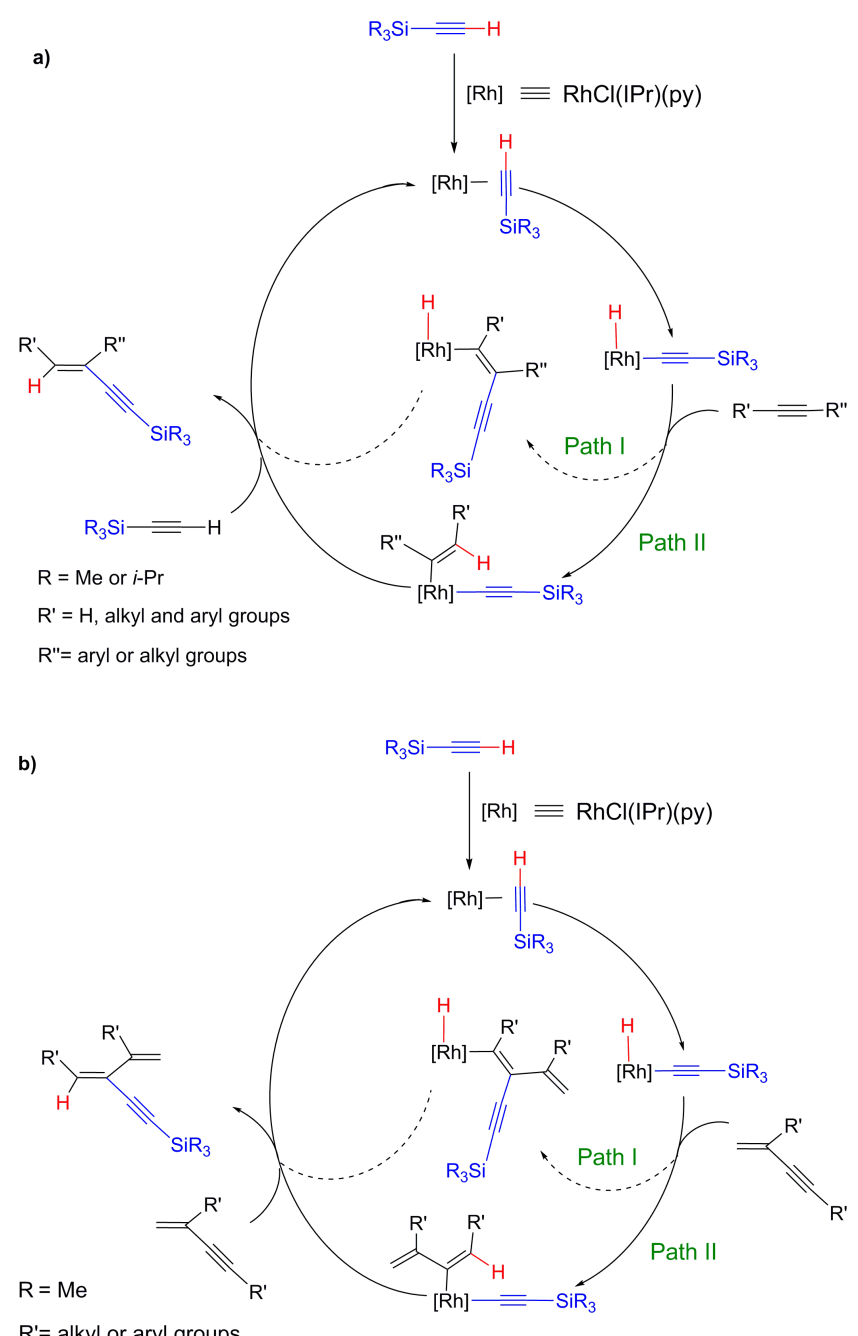

Scheme 6. A plausible mechanism for cross-dimerization and trimerization of alkynes.

\section{Conclusion}

In summary, we have described an efficient protocol for the selective head-to-tail cross-dimerization, and trimerization of silylacetylenes with alkynes promoted by a rhodium- $\mathrm{N}$ heterocyclic-carbene catalyst. This catalytic system is an alternative for the synthesis of elaborated enynes and dienynes, which are difficult to prepare by other available procedures. The reaction could be applied to a variety of terminal alkynes, symmetrical and unsymmetrical internal alkynes, and gem-1,3disubstituted enynes with substituents of different electronic character.

\section{Experimental Section}

General Information. All reactions were carried out with rigorous exclusion of air using Schlenk-tube techniques. All reagents are commercially available and were used as received, except for phenylacetylene that was distilled under argon and stored over molecular sieves. Organic solvents were dried by standard procedures and distilled under argon prior to use or obtained oxygen- and water-free from a Solvent Purification System (Innovative Technologies). The starting complexes $[\mathrm{Rh}(\mu-\mathrm{Cl})(\mathrm{IPr})$ $\left.\left(\eta^{2}-\mathrm{coe}\right)\right]_{2} 1,{ }^{[16]}$ and $\mathrm{RhCl}(\operatorname{IPr})\left(\eta^{2}-\mathrm{coe}\right)(\mathrm{py}), \mathbf{2}^{\left[{ }^{[13 \mathrm{~d}]}\right.}$ were prepared as previously described in the literature. ${ }^{1} \mathrm{H}$, and ${ }^{13} \mathrm{C}\left\{{ }^{1} \mathrm{H}\right\}$ NMR were 
recorder either a Bruker ARX $300 \mathrm{MHz}$ or a Bruker $400 \mathrm{MHz}$ instruments. Chemical shifts (expressed in parts per million) are referenced to residual solvent peaks $\left({ }^{1} \mathrm{H},{ }^{13} \mathrm{C}\left\{{ }^{1} \mathrm{H}\right\}\right)$. Coupling constants, $J$, are given in $\mathrm{Hz}$. Spectral assignments were achieved by combination of ${ }^{1} \mathrm{H}-{ }^{1} \mathrm{H}$ COSY, ${ }^{13} \mathrm{C}$ APT and ${ }^{1} \mathrm{H}-{ }^{13} \mathrm{C} \mathrm{HSQC} / \mathrm{HMBC}$ experiments. GC-MS analysis were recorder on an Agilent 5973 mass selective detector interfaced to an Agilent 6890 series gas chromatograph system, using a HP-5MS 5\% phenyl methyl siloxane column ( $30 \mathrm{~m} \times 250 \mathrm{~mm}$ with a $0.25 \mathrm{~mm}$ film thickness).

Catalytic cross-dimerization of silylacetylenes with terminal or internal alkynes. A NMR tube containing a solution of $0.01 \mathrm{mmol}$ of catalyst $2 \mathrm{a}(5 \mathrm{~mol} \%)$ in $0.5 \mathrm{ml}$ of $\mathrm{C}_{6} \mathrm{D}_{6}$ was treated with $0.2 \mathrm{mmol}$ of silylacetylene (3a or $3 \mathbf{b}$ ), $0.2 \mathrm{mmol}$ of terminal alkyne (4) or internal alkyne (9) and $0.1 \mathrm{mmol}$ of pyridine and heated at $80^{\circ} \mathrm{C}$. The conversion was monitored in a NMR apparatus and quantified by the integration of the ${ }^{1} \mathrm{H}$ NMR signals of the aliphatic or aromatic alkyne and the products formed.

General procedure for isolation of gem-1,3-disubstitutedenynes. In a Schlenk tube containing $0.02 \mathrm{mmol}$ of catalyst $\mathbf{2 a}, 0.2$ mmol of pyridine, $0.4 \mathrm{mmol}$ of silylacetylene (3a or $3 \mathbf{b}$ ) and 0.4 $\mathrm{mmol}$ of the terminal alkyne (4) or internal alkyne $(9)$ in $10 \mathrm{~mL}$ of toluene was stirred at $80^{\circ} \mathrm{C}$ for the time indicated in Table 1. The solution was analysed by GC-MS to quantify the remaining substrate, and was later concentrated under reduced pressure, affording a crude residue, which was purified by column chromatography over silica gel (70-230 mesh), and eluted with hexane-diethyl ether (99:1) to isolate the corresponding products.

General procedure for isolation of gem-1,3-disubstituteddienyne derivatives. In a Schlenk tube containing $0.02 \mathrm{mmol}$ of catalyst $2 \mathrm{a}, 0.4 \mathrm{mmol}$ of terminal alkyne (4) and $0.2 \mathrm{mmol}$ of pyridine in $10 \mathrm{~mL}$ of toluene was stirred at $40{ }^{\circ} \mathrm{C}$. When the corresponding alkyne was converted into gem-1,3-enyne (7), trimethylsilylacetylene (3a, $0.2 \mathrm{mmol}$ ) was added and heated at 80 ${ }^{\circ} \mathrm{C}$ for $12 \mathrm{~h}$. The solution was concentrated under reduced pressure, affording a crude residue, which was purified by column chromatography over silica gel (70-230 mesh), and eluted with hexane- diethyl ether $(90: 10)$ to isolate the corresponding dienynes (8).

NMR data for selected compounds (See Supporting Information for full NMR data of all compounds): 1-trimethylsilyl-3-phenylbut3-en-1-yne, (5a): Isolted as a colourless oil. Yield (71\%). ${ }^{1} \mathrm{H}$ NMR $\left(400 \mathrm{MHz}, \mathrm{C}_{6} \mathrm{D}_{6}, 298 \mathrm{~K}\right): \delta 7.81\left(\mathrm{~d}, \mathrm{~J}_{\mathrm{H}-\mathrm{H}}=8.3,2 \mathrm{H}, \mathrm{H}_{o-\mathrm{Ph}}\right), 7.23$ (dd, $\left.J_{\mathrm{H}-\mathrm{H}}=8.3,7.4,2 \mathrm{H}, \mathrm{H}_{m-\mathrm{Ph}}\right), 7.18\left(\mathrm{t}, J_{\mathrm{H}-\mathrm{H}}=7.4,1 \mathrm{H}, \mathrm{H}_{p-\mathrm{Ph}}\right), 5.80$ and 5.77 (both d, $\left.J_{\mathrm{H}-\mathrm{H}}=1.0,2 \mathrm{H}, \mathrm{H}_{4}\right), 0.31(\mathrm{~s}, 9 \mathrm{H}, \mathrm{SiMe}) .{ }^{13} \mathrm{C}\left\{{ }^{1} \mathrm{H}\right\}-\mathrm{APT}$ NMR plus HSQC and HMBC (100 MHz, $\mathrm{C}_{6} \mathrm{D}_{6}, 298 \mathrm{~K}$ ): $\delta 137.3$ (s, $\mathrm{C}_{q-\mathrm{Ph}}$ ), $131.1\left(\mathrm{~s}, \mathrm{C}_{3}\right.$ ), 128.5 and 128.4 (both s, $\mathrm{C}_{m, p-\mathrm{Ph}}$ ), 126.2 (s, $\mathrm{C}_{o-}$ $\mathrm{Ph}), 121.5\left(\mathrm{~s}, \mathrm{C}_{4}\right), 104.7\left(\mathrm{~s}, \mathrm{C}_{2}\right), 88.8\left(\mathrm{~s}, \mathrm{C}_{1}\right),-0.3$ (s, SiMe). GC/MS: $\mathrm{m} / \mathrm{z} 200 \quad\left(\mathrm{M}^{+}\right), \quad 185 \quad\left(\mathrm{M}^{+}-\mathrm{Me}\right), \quad 170, \quad 145, \quad 129, \quad 105 . \quad$ (E)-1trimethylsilyl-3-benzylidene-4-phenylpent-4-en-1-yne,

Isolated as a colorless oil. Yield (65\%). ${ }^{1} \mathrm{H}$ NMR $\left(400 \mathrm{MHz}, \mathrm{C}_{6} \mathrm{D}_{6}\right.$ $298 \mathrm{~K}$ ): $\delta 7.42\left(\mathrm{~d}, J_{\mathrm{H}-\mathrm{H}}=8.2,2 \mathrm{H}, \mathrm{H}_{o-\mathrm{Ph} \beta}\right), 7.15\left(\mathrm{~d}, J_{\mathrm{H}-\mathrm{H}}=8.0,2 \mathrm{H}, \mathrm{H}_{o-}\right.$ Pha $), 7.09\left(\mathrm{~s}, 1 \mathrm{H}, \mathrm{H}_{6}\right), 6.93\left(\mathrm{dd}, J_{\mathrm{H}-\mathrm{H}}=8.2,7.6,2 \mathrm{H}, \mathrm{H}_{m-\mathrm{Ph} \beta}\right), 6.89\left(\mathrm{t}, J_{\mathrm{H}-}\right.$ $\left.{ }_{\mathrm{H}}=7.6,1 \mathrm{H}, \mathrm{H}_{p-\mathrm{Ph} \beta}\right), 6.75\left(\mathrm{dd}, J_{\mathrm{H}-\mathrm{H}}=8.0,7.6,2 \mathrm{H}, \mathrm{H}_{m-\mathrm{Ph} \alpha}\right), 6.72\left(\mathrm{t}, J_{\mathrm{H}-\mathrm{H}}\right.$ $\left.=7.6,1 \mathrm{H}, \mathrm{H}_{p-\mathrm{Ph} \alpha}\right), 5.40$ and 5.25 (both $\left.\mathrm{d}, J_{\mathrm{H}-\mathrm{H}}=1.0,2 \mathrm{H}, \mathrm{H}_{5}\right), 0.00(\mathrm{~s}$, $9 \mathrm{H}$, SiMe). ${ }^{13} \mathrm{C}\left\{{ }^{1} \mathrm{H}\right\}-\mathrm{APT}$ NMR plus HSQC and HMBC $(100 \mathrm{MHz}$, $\mathrm{C}_{6} \mathrm{D}_{6}, 298 \mathrm{~K}$ ): $\delta 145.6\left(\mathrm{~s}, \mathrm{C}_{4}\right), 139.4\left(\mathrm{~s}, \mathrm{C}_{6}\right), 138.0\left(\mathrm{~s}, \mathrm{C}_{q-\mathrm{Ph} \beta}\right), 136.0$ $\left(\mathrm{s}, \mathrm{C}_{q-\mathrm{Ph} \alpha}\right.$ ), 129.4 (s, $\mathrm{C}_{o-\mathrm{Ph} \alpha}$ ), 128.7 and 128.6 (both $\mathrm{s}, \mathrm{C}_{m, p-\mathrm{Ph} \beta}$ ), 128.3 and 128.2 (both $\left.\mathrm{s}, \mathrm{C}_{m, p-\mathrm{Ph} \alpha}\right), 126.8\left(\mathrm{~s}, \mathrm{C}_{o-\mathrm{Ph} \beta}\right), 124.6\left(\mathrm{~s}, \mathrm{C}_{3}\right), 116.2$ (s, $\left.\mathrm{C}_{5}\right), 107.8\left(\mathrm{~s}, \mathrm{C}_{2}\right), 92.0\left(\mathrm{~s}, \mathrm{C}_{1}\right), 0.0$ (s, SiMe). HRMS (ESI) $\mathrm{m} / \mathrm{z}$ calcd for $\mathrm{C}_{21} \mathrm{H}_{22} \mathrm{Si}\left(\mathrm{M}^{+}+1\right), \quad 303.1564$, found 303.1544. (E)-1trimethylsilyl-3,4-diphenylbut-3-en-1-yne, (10b): Isolated as a colourless oil. Yield (91\%). ${ }^{1} \mathrm{H}$ NMR (400 MHz, C $\left.6 \mathrm{D}_{6}, 298 \mathrm{~K}\right): \delta 7.55$ $\left(\mathrm{d}, J_{\mathrm{H}-\mathrm{H}}=8.1,2 \mathrm{H}, \mathrm{H}_{o-\mathrm{Ph}}\right), 7.30\left(\mathrm{~s}, 1 \mathrm{H}, \mathrm{H}_{4}\right), 7.15-7.07\left(\mathrm{~m}, 6 \mathrm{H}, \mathrm{H}_{\mathrm{Ph}}\right)$, $6.98\left(\mathrm{~d}, \mathrm{~J}_{\mathrm{H}-\mathrm{H}}=8.1,2 \mathrm{H}, \mathrm{H}_{\mathrm{o}-\mathrm{Ph}}\right), 0.32(\mathrm{~s}, 9 \mathrm{H}, \mathrm{SiMe}) .{ }^{13} \mathrm{C}\left\{{ }^{1} \mathrm{H}\right\}-$ APT NMR plus HSQC and HMBC (100 MHz, $\left.\mathrm{C}_{6} \mathrm{D}_{6}, 298 \mathrm{~K}\right)$ : $\delta 137.8$ and 136.2 (both s, $\left.\mathrm{C}_{q-\mathrm{Ph}}\right), 137.6\left(\mathrm{~s}, \mathrm{C}_{4}\right), 129.5,129.2,128.6,128.2,127.8$, and 127.7 (all s, $\mathrm{C}_{\mathrm{Ph}}$ ), 124.7 (s, C $\left.\mathrm{C}_{3}\right), 108.4\left(\mathrm{~s}, \mathrm{C}_{2}\right), 94.5\left(\mathrm{~s}, \mathrm{C}_{1}\right),-0.1$ (s,
SiMe). HRMS (ESI) $m / z$ calcd for $\mathrm{C}_{19} \mathrm{H}_{20} \mathrm{Si}\left(\mathrm{M}^{+}+1\right), 277.1407$, found 277.1426.

\section{Acknowledgements}

Financial support from the Spanish Ministerio de Economía $y$ Competitividad (MEC/FEDER) of Spain Project (CTQ201015221), the Diputación General de Aragón (E07), the KFUPMUNIZAR agreement, and CONSOLIDER INGENIO-2010, under the Project MULTICAT (CSD2009-00050) are gratefully acknowledged. L. R.-P. thanks CONACyT (Mexico, 186898 and 204033) for a postdoctoral fellowship.

Keywords: C-C Coupling • Rhodium • Cross-Dimerization • Cross Trimerization $\cdot \mathrm{N}$-Heterocyclic Carbene

[1] a) B. M. Trost, Science 1991, 254, 1471-1477; b) K. C. Nicolau; W. M Dai, S. C. Tsay, V. A. Estevez, W. Wrasidlo, Science 1992, 256, 1172 1178; c) D. J. Faulkner, Nat. Prod. Rep. 2001, 18, 1-49; d) H. Katayama, M. Nakayama, T. Nakano, C. Wada, K. Akamatsu, F. Ozawa, Macromolecules 2004, 37, 13-17; e) S. E. Denmark, S.-M Yang, J. Am. Chem. Soc. 2004, 126, 12432-12440; f) Y. Liu, M. Nishiura, Y. Wang, Z. Hou, J. Am. Chem. Soc. 2006, 128, 5592-5593; g) M. Gholami, R. R. Tykwinski, Chem. Rev. 2006, 106, 4997-5027; h) W. P. Forrest, Z. Cao, H. R. Hambrick, B. M. Prentice, P. E. Fanwick, P. S. Wagenknecht, T. Ren, Eur. J. Inorg. Chem. 2012, 5616-5620.

[2] a) A. Haskel, J. Q. Wang, T. Straub, T. G. Neyroud, M. S. Eisen, J. Am. Chem. Soc. 1999, 121, 3025-3034; b) V. Ritleng, C. Sirlin, M. Pfeffer, Chem. Rev. 2002, 102, 1731-1769; c) H. Katayama, F. Ozawa, Coord. Chem. Rev. 2004, 248, 1703-1715; d) M. Nishiura, Z. Hou, J. Mol. Catal. A: Chem. 2004, 213, 101-106; e) E. Bustelo, P. H. Dixneuf in: Handbook of C-H Transformations, Vol. 1, (Ed: G. Dyker), Wiley-VCH, Weinheim, 2005, Chapter II.

[3] a) T. Hirabayashi, S. Sakaguchi, Y. Ishii, Adv. Synth. Catal. 2005, 347, 872-876; b) K. Ogata, O. Oka, A. Toyota, N. Suzuki, S.-i. Fukuzawa, Synlett 2008, 2663-2666.

[4] N. Matsuyama, H. Tsurugi, T. Satoh, M. Miura, Adv. Synth. Catal. 2008, 350, 2274-2278.

[5] a) B. M. Trost, C. Chan, G. Rühter, J. Am. Chem. Soc. 1987, 109 3486-3487; b) B. M. Trost, A. E. Harms, Tetrahedron Lett. 1996, 37 3971-3974; c) B. M. Trost, M. T. Sorum, C. Chan, A. E. Harms, G. Rühter, J. Am. Chem. Soc. 1997, 119, 698-708; d) B. M. Trost, M. C. Mcintosh, Tetrahedron Lett. 1997, 38, 3207-3210; e) L. Chen, C.-J. Li, Tetrahedron Lett. 2004, 45, 2771-2774; f) N. Tsukada, S. Ninomiya, Y. Aoyama, Y. Inoue, Org. Lett. 2007, 9, 2919-2921.

[6] a) W. Weng, C. Guo, R. Çelenligil-Çetin, B. M. Foxman, O. V. Ozerov Chem. Commun. 2006, 197-199; b) T. Katagiri, H. Tsurugi, A. Funayama, T. Satoh, M. Miura, Chem. Lett. 2007, 36, 830-831; c) T. Nishimura, X.-X. Guo, K. Ohnishi, T. Hayashi, Adv. Synth. Catal. 2007, 349, 2669-2672; d) J.-i. Ito, M. Kitase, H. Nishiyama, Organometallics 2007, 26, 6412-6417; e) T. Katagiri, H. Tsurugi, T. Satoh, M. Miura, Chem. Commun. 2008, 3405-3407; f) Y. Shibata, K. Tanaka, Angew. Chem. Int. Ed. 2011, 50, 10917-10921; g) K. Ogata, I. Ohashi, S.-i. Fukuzawa, Org. Lett. 2012, 14, 4214-4217; h) H.-D. Xu, R.-W. Zhang, X. Li, S. Huang, W. Tang, W.-H. Hu, Org. Lett. 2013, 15, 840-843.

[7] a) C. S. Yi, N. Liu, Organometallics 1998, 17, 3158-3160; b) H. Katayama, H. Yari, M. Tanaka, F. Ozawa, Chem. Commun. 2005 , 4336-4338.

[8] a) M. Akita, H. Yasuda, A. Nakamura, Bull. Chem. Soc. Jpn. 1984, 57, 480-487; b) G. V. Oshovsky, B. Hessen, J. N. H. Reek, B. de Bruin, Organometallics. 2011, 30, 6067-6070.

[9] a) T. Sakurada, Y.-k. Sugiyama, S. Okamoto, J. Org. Chem. 2013, 78, 3583-3591; b) T. Sawano, K. Ou, T. Nishimura, T. Hayashi, J. Org Chem. 2013, 78, 8986-8993.

[10] a) S. L. Buchwald, R. B. Nielsen, J. Am. Chem. Soc. 1989, 111, 2870 2874; b) Y. Kido, M. Yamaguchi, J. Org. Chem. 1998, 63, 8086-8087; c) A. K. Dash, M. S. Eisen, Org. Lett. 2000, 2, 737-740; d) J. Wang, M. 
Kapon, J. C. Bertet, M. Ephritikhine, M. S. Eisen, Inorg. Chim. Acta 2002, 334, 183-192; d) B. M. Trost, B. R. Taft, J. T. Masters, J.-P Lumb, J. Am. Chem. Soc. 2011, 133, 8502-8505; e) M. Yoshimatsu, H. Sasaki, Y. Sugimoto, Y. Nagase, G. Tanabe, O. Muraoka Org. Lett. 2012, 14, 3190-3193.

[11] A. J. Kresge, P. Pruszinsky, P. J. Stang, B. L. Williamson, J. Org. Chem. 1991, 56, 4808-4811.

[12] Selected examples of cross trimerization by Ni, see: a) K. Ogata, H. Murayama, J. Sugasawa, N. Suzuki, S.-i. Fukuzawa, J. Am. Chem. Soc. 2009, 131, 3176-3177; b) K. Ogata, J. Sugasawa, S.-i. Fukuzawa, Angew. Chem. Int. Ed. 2009, 48, 6078-6080; c) K. Ogata, J. Sugasawa, Y. Atsuumi, S.-i. Fukuzawa, Org. Lett. 2010, 12, 148-151; d) K. Ogata, Y. Atsuumi, S.-i. Fukuzawa, Org. Lett. 2011, 13, 122-125.

[13] a) M. V. Jiménez, J. J. Pérez-Torrente, M. I. Bartolomé, V. Gierz, F. J. Lahoz, L. A. Oro, Organometallics. 2008, 27, 224-234; b) L. Palacios, X. Miao, A. Di Giuseppe, S. Pascal, C. Cunchillos, R. Castarlenas, J. J. Pérez-Torrente, F. J. Lahoz, P. H. Dixneuf, L. A. Oro, Organometallics. 2011, 30, 5208-5213; c) I. Mena, M. A. Casado, P. García-Orduña, V Polo, F. J. Lahoz, A. Fazal, L. A. Oro, Angew. Chem. Int. Ed. 2011, 50, 11735-11738; d) A. Di Giuseppe, R. Castarlenas, J. J. Pérez-Torrente,
M. Crucianelli, V. Polo, R. Sancho, F. J. Lahoz, L. A. Oro, J. Am. Chem. Soc. 2012, 134, 8171-8183; e) R. Azpíroz, A. Di Giuseppe, R. Castarlenas, J. J. Pérez-Torrente, L. A. Oro, Chem. Eur. J. 2013, 19 3812-3816; f) L. Rubio-Pérez, R. Azpíroz, A. Di Giuseppe, V. Polo, R. Castarlenas, J. J. Pérez-Torrente, L. A. Oro, Chem. Eur. J. 2013, 19 15304-15314; g) L. Palacios, A. Di Giuseppe, A. Opalinska, R. Castarlenas, J. J. Pérez-Torrente, F. J. Lahoz, L. A. Oro, Organometallics 2013, 32, 2768-2774; h) L. Palacios, M. J. Artigas, V. Polo, F. J. Lahoz, R. Castarlenas, J. J. Pérez-Torrente, L. A. Oro, ACS Catalysis 2013, 3, 2910-2919; i) G. Lázaro, M. Iglesias, F. J. Fernández-Alvarez, P. J. Sanz-Miguel, J. J. Pérez-Torrente, L. A. Oro, ChemCatChem 2013, 5, 1133-1141.

[14] The alkyne cross-dimerization performed with catalyst $2 a$ in the absence of added pyridine resulted in the formation of cyclotrimers as byproducts. See ref $13 \mathrm{f}$.

[15] a) G. C. M. Lee, B. Tobias, J. M. Holmes, D. A. Harcourt, M. E. Garst, J. Am. Chem. Soc. 1990, 112, 9330-9336; b) R. R. Singidi, T. V. Rajanbabu, Org. Lett. 2010, 12, 2622-2625.

[16] X.Y. Yu, B. O. Patrick, B. R. James, Organometallics. 2006, 25, 4870 4877. 
